\title{
Víctimas de violencia intrafamiliar y la reparación integral en el Ecuador
}

\author{
Victims of intrafamily violence and integral reparation in Ecuador
}

Fátima Lizbeth Espín Rojas. ${ }^{1}$ \& Danny Xavier Sánchez Oviedo. ${ }^{2}$

\begin{abstract}
DOI: https://doi.org/10.33262/concienciadigital.v4i4.1883

Introduction. Violence against women, in the family nucleus, must be understood as any type of affectation by a family member directed towards the woman, having to understand that this can be of different types, including physical, psychological, sexual and economic or patrimonial. Intervention and protection by the State to victims of such acts is fundamental and one of its main pillars is to ensure adequate integral reparation. Thus, we could establish that full reparation is to return to the state before the violation of the rights of women victims of violence as largely as possible which can be achieved through different mechanisms and repair standards. Objective. This paper presents and develops the issue of violence against women in the domestic or domestic environment in Ecuador and parameters for adequate integral reparation. Methodology. The research has been conducted from a literature methodology (qualitative) by which analyzed relevant documents to the subject, national legislation, international conventions, judgments of the Inter-American Court and Constitutional Court. Results. With academic information obtained allowed us to pinpoint the types of violence that are generated in the domestic sphere. Furthermore, it has come to set parameters and mechanisms must be addressed for full compensation is applied effectively and efficiently. Conclusion. It has been
\end{abstract}

${ }^{1}$ Universidad Tecnológica Indoamérica, Facultad de Jurisprudencia, Ciencias Políticas y Económicas, Carrera de Derecho, Tungurahua, Ecuador. fespin4@indoamerica.edu.ec lizbethespinrojas@ hotmail.com.ec; ORCID: https://orcid.org/0000-0003-4031-2925

${ }^{2}$ Universidad Tecnológica Indoamérica, Facultad de Jurisprudencia, Ciencias Políticas y Económicas, Carrera de Derecho, Tungurahua, Ecuador. dannysanchez@uti.edu.ec; ORCID: https://orcid.org/00000001-5783-2682 
established that it is an obligation of the State to guarantee that the victims of intrafamily or domestic violence are recognized of their right to comprehensive reparation due to the violence which they have been a victim, therefore, the Constitution as well as the Legal regulations establish the mechanisms and parameters for effective reparation, which aims to minimize the impact on the victim.

Keywords: Domestic Violence, Integral Repair, Victim, Restitution.

\section{Resumen}

Introducción. La violencia contra la mujer, en el núcleo familiar debe entenderse como todo tipo de afectación por parte de un miembro de la familia dirigida hacia la mujer, debiendo comprender que esta puede ser de diferentes tipos, entre ellas física, psicológica, sexual y económica o patrimonial. La intervención y protección por parte del Estado a las víctimas de esta clase de actos es fundamental y uno de sus principales ejes consiste en garantizar una adecuada reparación integral. Así, podríamos establecer que la reparación integral consiste en volver al estado anterior a la violación de los derechos de la mujer víctima de violencia en lo mayormente posible lo cual se puede conseguir a través de los diferentes mecanismos y estándares de reparación. Objetivo. El presente trabajo plantea y desarrolla el tema de la violencia contra la mujer en el ámbito intrafamiliar o doméstico en Ecuador y los parámetros para una adecuada reparación integral. Metodología. La investigación se ha realizado desde una metodología bibliográfica (cualitativa) mediante la cual se analizó documentos relevantes al tema; la legislación nacional, convenios internacionales, sentencias de la Corte IDH y Corte Constitucional. Resultados. Con la información académica obtenida nos ha permitido establecer claramente los tipos de violencia que se generan en el ámbito intrafamiliar. Además se ha llegado a establecer los parámetros y mecanismos que se deben abordar para que la reparación integral sea aplicada de manera efectiva y eficaz. Conclusión. Se ha llegado a establecer que es una obligación del Estado el garantizar que las víctimas de violencia intrafamiliar o domestica sean reconocidas de su derecho a la reparación integral a causa de la violencia la cual ha sido víctima, por lo tanto, la Constitución así como la normativa jurídica establece los mecanismos y parámetros para la efectiva reparación con lo que se propende minimizar el impacto en la victima.

Palabras Claves: Violencia Intrafamiliar, Reparación Integral, Victima, Restitución.

\section{Introducción}

Con el paso de los años la legislación ecuatoriana ha generado grandes cambios sobre el tratamiento de la violencia intrafamiliar, pues, esta ha venido en constante evolución, buscando mecanismos legales para bajar los índices de violencia doméstica, misma que pese a los grandes esfuerzos realizados a nivel legislativo y judicial, lamentablemente no se ha logrado ni controlar y menos reducir este problema social, así se determina con la información reflejada por el Instituto Nacional de Estadísticas y Censos, ya que de 
acuerdo a la encuesta Nacional de Relaciones Familiares y Violencia de Genero contra las Mujeres realizada en el 2011, tenemos que, a este año las mujeres que han vivido algún tipo de violencia de genero a nivel nacional se ubicaba en el 60.6\% (Instituto Nacional de Estadisticas y Censos, 2011), mientras que para el año 2019, el porcentaje de mujeres que ha vivido algún tipo de violencia de genero se ubica en el 64.9\% (Instituto Nacional de Estadisticas y Censos, 2019).

La Ley Contra la Violencia a la mujer y la familia configuraba tres tipos o formas de violencia intrafamiliar, violencia física, psicológica y sexual, para las mismas que se contemplaban sanciones privativas de libertad, con excepción de la psicológica que merecía sanción no privativa de libertad (Ley contra la violencia a la mujer y la familia, 1995), formas o tipo de violencia que se incorporan como tipos penales en el Código Orgánico Integral Penal en calidad de figuras delictivas merecedoras de penas privativas de libertad a partir del mes de agosto del 2014; y, no es sino hasta el cinco de febrero de 2018 que se configuran a más de las formas de violencia intrafamiliar de tipo físico, psicológico y sexual dentro del ámbito familiar otro tipo de violencia, la económica y patrimonial (Ley Organica Integral para prevenir y erradicar la violencia contra las mujeres, 2018), aunque también aparecen otras de tipo simbólica, política y ginecoobstétrica, no obstante, estas no estarían ejercidas dentro del núcleo familiar.

En la Ley contra la violencia a la mujer y la familia (Ley 103 derogada), si bien es cierto se establecían sanciones para las formas de violencia física y psicológica en el ámbito contravencional y en caso de violencia física que constituía delito, además de la sexual se remitían a las sanciones determinadas en el Código Penal que pierde vigencia el 09 de agosto del 2014 por la entrada en vigencia del Código Orgánico Integral Penal, pero esta no contemplaba parámetros de determinación de una reparación integral en favor de las víctimas de violencia intrafamiliar, lo cual generaba que las comisarías de la mujer y la familia existentes en aquel entonces casi nunca establezcan medidas de reparación integral, limitándose en varios de los casos únicamente a determinarse el pago de una cierta cantidad de dinero como efectos de una reparación, a pesar de la existencia de convenios internacionales de Derechos Humanos que garantizaban la misma y es apenas en el año 2018 que entra en vigencia la Ley Orgánica Integral para prevenir y erradicar la violencia contra las mujeres que establece parámetros claros respecto de la reparación integral en favor de las víctimas de violencia intrafamiliar, desarrollándose de esta manera, lo que ya se encontraba determinado de forma general en la Constitución de la República del Ecuador.

A nivel de sistema de justicia, aun cuando se encuentran desarrollados los parámetros y estándares a ser observados al momento de disponer la reparación integral, hasta la actualidad no se ha conseguido que los fallos emanados contemplen todos los mecanismos de reparación integral, pues en muchos casos tan solo se contemplan reparaciones económicas, mismas que incluso resultan inferiores a las que se impone por concepto de multa, es por eso que en el presente artículo procuramos responder a las interrogantes planteadas, tales como: ¿Se ha desarrollado en el contexto jurídico ecuatoriano, parámetros o estándares aplicables para la reparación integral a favor de las 
víctimas de violencia intrafamiliar? ¿El sistema de justicia ecuatoriano, dispone de medidas de reparación integral en favor de las víctimas de violencia domestica conforme a los estándares nacionales e internacionales de Derechos Humanos?, lo cual, hemos contextualizado a partir del marco jurídico ecuatoriano, tratados internacionales de Derechos Humanos, sentencias de Corte Interamericana de Derechos Humanos y diversos estudios contenidos en documentos investigativos escritos al respecto.

Este trabajo investigativo bibliográfico lo hemos dividido en tres secciones, la primera que corresponde a un análisis jurídico normativo nacional e internacional de Derechos Humanos, así como, en base a estudios realizados sobre la reparación integral a las víctimas de violencia intrafamiliar y sus estándares aplicativos; la segunda en lo que respecta a la aplicación práctica de los estándares sobre reparación integral de las víctimas de violencia intrafamiliar desarrollados en la normativa; y, la tercera contiene las conclusiones.

\section{La violencia contra la mujer en el ámbito familiar o domestico}

Es importante establecer aspectos sobre la violencia contra la mujer de forma general para luego poder trasladarse al ámbito de violencia familiar y así definir los actores que intervienen dentro de la violencia doméstica al igual como esta afecta e incide sobre la mujer que la sufre, para ello partimos de lo que menciona las Naciones Unidas en el informe de la cuarta conferencia mundial sobre la mujer, reunida en Beijing del 4 al 15 de septiembre del 1995, en la misma se establece como definición sobre violencia contra la mujer en su párrafo 113, al manifestar que esta es:

"Todo acto de violencia basado en el género que tiene como resultado posible o real un daño físico, sexual o psicológico, incluidas las amenazas, la coerción o la privación arbitraria de la libertad, ya sea que ocurra en la vida pública o privada" (ONU, Informe de la Cuarta Conferencia Mundial sobre la Mujer - Beijing , 1996, pág. 51)

En el mismo informe se manifiesta que:

"La violencia contra la mujer es una manifestación de las relaciones de poder históricamente desiguales entre hombres y mujeres, que han conducido a la dominación de la mujer por el hombre, la discriminación contra la mujer y a la interposición de obstáculos contra su pleno desarrollo..." (ONU, Informe de la Cuarta Conferencia Mundial sobre la Mujer - Beijing, 1996, pág. 52)

La violencia contra la mujer germina en la sociedad mundial el momento en que creamos patrones socioculturales en los seres humanos, mismos que provienen desde su nacimiento con la utilización de estereotipos que luego con el crecimiento de la persona estos se han fijado en su pensamiento e ideología.

La violencia simbólica se constituye como uno de los tipos de violencia contra la mujer a través del cual se ha impuesto la dominación ideológica del hombre sobre la mujer, tipo 
de violencia que ha sido reconocida y admitida por el grupo dominado. Mediante la violencia simbólica se ha provocado una mezcla entre lo biológico y lo social con la única finalidad de justificar la desigualdad generada por el hombre y que ha sido ratificada por la cultura, habiendo provocado con esto la prevalencia y persistencia de las desigualdades sociales que se ha profundizado en discriminación ejercida en un inicio desde la ideología por parte del hombre hacia la mujer desembocando aquello en actos de violencia que no solamente quedan en ideológico o simbólico sino que se transforman en prácticas agresivas en el aspecto físico, psicológicas e incluyendo el sexual (Alberdi \& Matas, 2002).

Diversos son los ámbitos en los cuales en Ecuador, la mujer resulta ser víctima de violencia, entre ellos la violencia intrafamiliar o doméstica, educativa, laboral, deportiva, estatal e institucional, en los centros de privación de libertad, mediático y cibernético, en los espacios públicos o comunitarios, en centros e instituciones de salud, en emergencias y situaciones humanitarias (Ley Organica Integral para prevenir y erradicar la violencia contra las mujeres, 2018), ámbitos en los cuales de una u otra manera se ejercen actos de violencia en cualquiera de los tipos, ya sea física, psicológica, sexual, simbólica, entre otras, mismas que menoscaban los derechos de las mujeres a la igualdad, a una vida libre de violencia, así como, ser tratadas con respecto y dignidad.

La violencia contra la mujer en el ámbito familiar, conocida como intrafamiliar o doméstica, es aquella entendida como, la violencia desarrollada en el entorno familiar constituida en los actos de abuso que cometen unos miembros de la familia en contra de otros, siendo estos de tipo físico, psicológico, sexual, etc., los cuales pueden causar un daño, sufrimiento físico, psicológico, sexual o inclusive pueden llegar a causar la muerte de la víctima (Karina, Ana, \& Wnellis, 2010).

La violencia doméstica es aquella que esta ejercida por una persona que es parte o miembro del núcleo familiar cuyas víctimas generalmente son quienes compartan o hayan compartido el núcleo familiar y en contra de quienes se haya infligido dolor y sufrimiento de cualquier tipo, actos de violencia que generalmente se cometen por el hombre en contra de la mujer (esposa e hijas), con la finalidad de mantener el control y ejercer poder en contra de las víctimas, lo cual es producto de la influencia de una sociedad patriarcal en la cual aún vivimos.

El Ecuador en su desarrollo normativo ha venido incorporando disposiciones legales encaminadas a prevenir, proteger y sancionar los actos de violencia de género, con mayor énfasis a partir del año 2014 en el cual entra en vigencia el Código Orgánico Integral Penal, año en el cual se incorpora como tipo delictivo la violencia psicológica ejercida como violencia intrafamiliar, violencia que en vigencia de la ley 103 era considerara tan solo como acción contravencional a más de los tipos de violencia física y sexual. Es en el año 2014, cuando se tipifica como delito la violencia psicológica, configurándose en aquel entonces la sanción penal acorde a la afectación que se ha generado en la victima en su ámbito psicológico, figura penal que sería objeto de reforma en el año 2018 cuando 
se promulga y entra en vigencia la Ley Orgánica Integral para prevenir y erradicar la violencia contra las mujeres.

El 5 de febrero del 2018 fue publicada e inmediatamente entra en vigencia la Ley Orgánica Integral para prevenir y erradicar la violencia contra las mujeres, ley que es producto de la adecuación normativa con la Constitución de la República del Ecuador y con los Convenios Internacionales de Derechos Humanos en los cuales se ha desarrollados los derechos humanos de la mujer, en este cuerpo normativo se introduce reformas orientadas básicamente a la prevención de la violencia contra la mujer pero también se introducen reformas al sistema penal con la finalidad de sancionar de forma severa los actos de violencia contra la mujer. Es en esta ley en la cual se configura a la violencia intrafamiliar o doméstica, misma que en su artículo 12 establece los ámbitos en los cuales se desarrolla la violencia contra las mujeres, configurándose en su numeral 1, la violencia intrafamiliar o doméstico, describiéndose como:

“Comprende el contexto en el que la violencia es ejercida en el núcleo familiar. La violencia es ejecutada por parte del cónyuge, la pareja en unión de hecho, el conviviente, los ascendientes, los descendientes, las hermanas, los hermanos, los parientes por consanguinidad y afinidad y las personas con las que la víctima mantenga o haya mantenido vínculos familiares, íntimos, afectivos, conyugales, de convivencia, noviazgo o de cohabitación" (Ley Organica Integral para prevenir y erradicar la violencia contra las mujeres, 2018).

Dentro de la violencia intrafamiliar resulta mucho más frecuente y en mayores porcentajes la violencia ejercida por el hombre contra su cónyuge o personas con las que mantenga o haya mantenido vínculos de convivencia, íntimos, de noviazgo o habitación, es decir violencia contra las personas que exista convivencia actual o haya existido convivencia en un determinado periodo de tiempo, pero que sin embargo, pese a que ya no existe vínculos actuales de convivencia, los actos de violencia persisten constituyéndose en una forma de ejecución del patriarcado en donde se busca la sumisión de las mujeres al poder del hombre. (Instituto Nacional de Estadisticas y Censos, 2019)

Sobre esta forma de dominación que genera violencia contra la mujer, las Naciones Unidas, en el informe de la cuarta conferencia mundial sobre la mujer, reunida en Beijing del 4 al 15 de septiembre del 1995, dice:

"Históricamente, los roles de género - los roles socialmente construidos de las mujeres y los hombres -han estado ordenados jerárquicamente, de tal modo que los hombres ejercen poder y control sobre las mujeres. La dominación masculina y la subordinación femenina tienen bases ideológicas y materiales. El patriarcado se ha abroquelado en normas sociales y culturales, y se encuentra institucionalizado en el derecho y en las estructuras políticas e incrustado en las economías locales y mundial. También se ha arraigado en las ideologías formales y en el discurso 
público..." (ONU, Estudio a fondo sobre todas las formas de violencia contra la mujer, 2006, pág. 32)

Hemos podido identificar que en Ecuador los porcentajes de violencia intrafamiliar o domestica alcanzan índices muy altos, de los cuales prevalece la violencia ejecutada por los cónyuges, convivientes o ex convivientes en contra de las mujeres, pero también existen actos de violencia ejecutados por el resto de miembros del núcleo familiar en contra de las mujeres y de diferente tipo, aunque resulta siendo siempre predominante el maltrato en contra de sus esposas, convivientes o ex convivientes, manifestándose en todo tipo de actos de violencia. (Instituto Nacional de Estadisticas y Censos, 2019)

Al respecto, Inés Alberdi y Natalia Matas, refieren:

La violencia familiar contra las mujeres puede provenir también de otros miembros de la familia como el padre, los hermanos y otros parientes; y puede ser física o psíquica. La violencia física tiene muchas formas y muchos grados, pudiendo ir desde los empujones y bofetadas hasta golpes que pueden provocar la muerte. En el ambiente familiar también se produce una violencia sexual, que se presenta en una amplia gradación, pues puede ir desde las burlas y comentarios ofensivos hasta la imposición de actos sexuales que la mujer desea rechazar. La violencia psíquica incorpora todas aquellas formas de tratar a las mujeres que limitan su libertad o niegan sus derechos y su dignidad. Pueden considerarse como tal los insultos, los desprecios, la adjudicación estereotipada de tareas serviles, la limitación a su capacidad de trabajar, así como la limitación para contactar con amigos y familiares. A veces se habla también de violencia económica para referirse a aquellas situaciones en que las mujeres tienen limitada su capacidad de obrar, de trabajar, de recibir un salario o de administrar sus bienes, por el hecho de ser mujeres situaciones todas ellas que la sitúan en una posición de inferioridad y desigualdad social (Alberdi \& Matas, 2002, pág. 79).

\section{Tipos de violencia dentro del ámbito familiar o domestico}

De acuerdo al informe referido por la Encuesta Nacional sobre Relaciones Familiares y violencia de género contra las mujeres ENVIGMU 2019, se determina que en Ecuador son cuatro los tipos de violencia que se ejecutan dentro del ámbito familiar o doméstico independiente del resto de tipos de violencia que se encuentran configurados en la normativa legal, estos tipos de violencia corresponden a la violencia psicológica, física, sexual y patrimonial o económica. (Instituto Nacional de Estadisticas y Censos, 2019)

La Organización de las Naciones Unidas, en el documento sobre el Estudio a fondo sobre todas las formas de violencia contra la mujer, ha manifestado que "la violencia psicológica consiste en actos tendiente a controlar o aislar a la mujer, así como a humillarla o avergonzarla (ONU, 2006, pág. 43). La violencia psicológica se ve reflejada 
en todo tipo de acciones o patrones de conducta que está encaminado a causar daño emocional ya sea mediante actos de manipulación emocional, control de creencias, acoso, hostigamiento, todo tipo de conducta abusiva, palabras, actos, gestos, mensajes escritos, electrónicos dirigidos a perseguir, intimidar, chantajear, vigilar a la mujer y que pueden afectar su estabilidad emocional, dignidad, prestigio e integridad psíquica y que causan efectos negativos, en su trabajo, educación y todo tipo de actividad que desarrolla la mujer (Ley Organica Integral para prevenir y erradicar la violencia contra las mujeres, 2018)

Sobre la violencia física, Inés Alberdi y Natalia Matas, han mencionado que:

“...es maltrato físico cualquier conducta que suponga agresión física contra la mujer. Pueden ser empujones, bofetadas, patadas, estrangulamientos, etc., que pueden ser actos realizados con objetos contundentes, como un palo o un cinturón, o ser realizadas con armas blancas como cuchillos o objetos cortantes (Sic)" (Alberdi \& Matas, 2002, pág. 92).

La violencia física a diferencia de la violencia psicológica contra la mujer se muestra mediante actos de obra ejecutados contra el físico de la víctima, sin embargo, no resulta más grave que la violencia psicológica ya que esta última también causa graves efectos sobre la psiquis de la persona y ocasiona perjuicio en la salud.

La violencia sexual, se constituye en todos aquellos actos ejecutados en contra de la integridad sexual de la mujer dentro del núcleo familiar o doméstico, misma que puede llegar incluso a la violación, se encuentra configurada a través de actos ejecutados por el marido en contra de su mujer habiendo sido sometida de forma física o psicológica para ejercer el contacto sexual cuando ésta no lo ha consentido. Alberdi y Matas, sobre la violencia sexual en el ámbito familiar o domestico refieren:

"La violencia sexual se ejerce mediante presiones psíquicas o físicas que imponen relaciones sexuales no deseadas mediante coacción, intimidación o indefensión. El maltrato sexual se produce cuando se obliga a la mujer a mantener relaciones sexuales contra su voluntad, o en una forma que ella no quiere ya sea por la fuerza o mediante coacciones" (Alberdi \& Matas, 2002, pág. 94).

La violencia patrimonial o económica, es un tipo de violencia que se genera en contra de la mujer en todos los ámbitos dentro de los cuales el ámbito familiar o doméstico tanto en las sociedad conyugal o sociedad de bienes, produciéndose este tipo de violencia al negárselo el derecho a disponer de los bienes o recursos económicos de forma absolutamente libre, en donde, éstos no estén sujetos a control alguno sobre su dominio. Este tipo de violencia en Ecuador aparece el 05 de febrero del 2018 y se configura por actos de perturbación de la posesión, tenencia o propiedad de los bienes muebles o inmuebles; perdida, sustracción, destrucción, apropiación o retención indebida de objetos, instrumentos de trabajo, documentos personales, bienes valores; limitación o control de 
los ingresos (Ley Organica Integral para prevenir y erradicar la violencia contra las mujeres, 2018).

Estos son los tipos de violencia que se ejercen o configuran dentro del ámbito de violencia intrafamiliar o doméstico y de los cuales se ha podido dar cuenta sobre su existencia, estableciéndose un porcentaje más alto de acuerdo a las estadísticas del INEC en base a sus estudios del 2019, a la violencia psicológica en un 40.8\%, encasillándose en último lugar la violencia sexual con un $8.3 \%$, del cual, conforme la reforma introducida al Código Orgánico Integral Penal de diciembre del año 2019, en vigencia a partir de junio del 2020, se establece sanciones más drásticas para los delitos sexuales que se producen como manifestación de violencia contra la mujer o miembros del núcleo familiar y que pertenezcan a grupos de atención prioritaria como niños, niñas y adolescentes, personas adultas mayores y personas con discapacidad. (Ley Reformatoria al Código Orgánico Integral Penal, 2019)

\section{La Reparación Integral}

Todo daño causado a la mujer dentro del ámbito de violencia intrafamiliar o domestica conlleva la imposición de una sanción acorde al daño y gravedad de la misma y ésta provoca a su vez la imposición de la obligación de la correspondiente reparación por los daños ocasionados, reparación que en términos generales significaría restablecer en lo posible a la situación anterior al daño (restitutio in integrum) y que de no ser esto posible se debe adoptar una serie de medidas encaminadas a garantizar los derechos conculcados, reparar las consecuencias que las infracciones produjeron, así como establecer el pago de una indemnización como compensación por el daño ocasionado (Caso Acevedo Jaramillo y otros Vs. Perú, 2006).

La definición más adecuada que se puede establecer sobre la reparación del daño causado es la que se contempla en la sentencia emanada por la Corte IDH, dentro del caso Acevedo Jaramillo Vs. Perú, misma que en el párrafo 297 establece:

"Las reparaciones son medidas que tienden hacer desaparecer los efectos de las violaciones cometidas. Su naturaleza y su monto dependen de la característica de la violación y de los daños ocasionados en el plano material e inmaterial. No puede implicar enriquecimiento ni empobrecimiento para la víctima o sus sucesores, y deben guardar relación con las violaciones declaradas en sentencia" (Caso Acevedo Jaramillo y otros Vs. Perú, 2006)

Ecuador, desde su normativa constitucional ha contemplado dentro de los derechos, al de las víctimas y su reparación integral, la Constitución en su Art. 78 establece “...Se adoptará mecanismos para una reparación integral que incluirá, sin dilaciones, el conocimiento de la verdad de los hechos y la restitución, indemnización, rehabilitación, garantía de no repetición y satisfacción del derecho violado" (Constitución de la República del Ecuador, 2008). Lo cual, dentro de los derechos de protección y que harían referencia a las víctimas directas de infracciones en general, toda vez que, también en la 
Constitución se contempla la reparación integral dentro de las garantías jurisdiccionales que corresponderían directamente a la aplicación al resolver estas garantías.

Dentro de la presente investigación, tratamos de acciones ejecutadas contra las mujeres en el ámbito familiar o doméstico, configuradas como infracciones penales (Codigo Orgánico Integral Penal, 2014), mismas que merecen la imposición de una sanción, lo cual conlleva a la respectiva reparación integral de las víctimas. Con la entrada en vigencia del nuevo sistema penal a partir del año 2014 se introduce dentro de su normativa reglas o disposiciones específicas relacionadas a las víctimas, configurándose dentro de sus derechos:

"A la adopción de mecanismos para la reparación integral de los daños sufridos que incluye, sin dilaciones, el conocimiento de la verdad de los hechos, el restablecimiento del derecho lesionado, la indemnización, la garantía de no repetición de la infracción, la satisfacción del derecho violado y cualquier otra forma de reparación adicional que se justifique en cada caso" (Codigo Orgánico Integral Penal, 2014).

Es a partir del 5 de febrero del año 2018 en el cual se establecen disposiciones claras sobre la reparación integral para las mujeres en sus calidades de víctimas de violencia de cualquier tipo y en cualquiera de los ámbitos contemplándose en la normativa un eje de reparación mediante medidas de acción afirmativa (Ley Organica Integral para prevenir y erradicar la violencia contra las mujeres, 2018).

Se deberá necesariamente ordenar la reparación material por el daño material e inmaterial causado, dentro de las cuales se podrá incluir la restitución del derecho vulnerado, compensación económica o patrimonial, la rehabilitación, satisfacción, garantía de que el hecho no se repita, disculpas públicas, entre otras. (Ley Organica Integral para prevenir y erradicar la violencia contra las mujeres, 2018). Entendiéndose por daño material todo aquello que provoca la pérdida o disminución de los ingresos de las víctimas, dentro de los cuales el daño emergente, lucro cesante y las costas y gastos en los que ha incurrido a causa de la infracción; mientras que por daño inmaterial debe comprenderse a todos los sufrimientos, aflicciones y todo tipo de alteración no pecuniaria sufridas por las víctimas y sus familiares, en los cuales se incluye el daño a la esfera moral, física, psicológica, proyecto de vida de la persona. (Storini, 2014)

En la actualidad se habla ya, de mecanismos para la reparación integral específicamente en lo que corresponde a mujeres víctimas de violencia, normativamente se ha determinado que la atención que deben recibir corresponde a una justicia especializada por todos los organismos de justicias y otras instituciones del Estado involucradas en esta problemática social, en la cual figuran la Fiscalía, Consejo de la Judicatura y Defensoría Pública, entidades que están obligadas a velar que las decisiones de los organismos jurisdiccionales encargados de administrar justicia resuelvan sobre una reparación integral real, sería y justa, así como a velar por el cumplimiento de la mismas a través de 
los seguimientos respectivos (Ley Organica Integral para prevenir y erradicar la violencia contra las mujeres, 2018)

Concomitante con lo anterior, se ha pronunciado la presidencia de la Corte Nacional de Justicia del Ecuador, al manifestar que:

“...evidente resulta que una vez que se encuentra vigente la Ley Orgánica Integral para Prevenir y Erradicar la violencia contra las mujeres, los criterios que en ella encontramos con relación a la reparación integral a favor de la víctima, deben ser los que orienten la actividad de los operadores de justicia.

Debemos indicar que la aplicación de los artículos 62 y 63 de la LOIPEVM, ley especial, posterior y más favorable, en aplicación con el artículo 622.6 del COIP, resulta además del apego al principio pro víctima y a la especial valoración de la prueba en materia de violencia contra las mujeres, reconocido por la doctrina, la jurisprudencia nacional y supranacional y a los estándares incorporados en diversos instrumentos internacionales que por sobre la materia ha suscrito el Ecuador" (Presidencia de la Corte Nacional de Justicia de Ecuador, 2020)

\section{El conocimiento de la verdad como medio de reparación}

El conocimiento de la verdad de los hechos se constituye como uno de los elementos dentro de los derechos de la reparación integral a las víctimas, este, es un aspecto que esta contemplado en la normativa nacional, lo cual ha sido recogido del sistema interamericano ya que así se ha pronunciado la Corte Interamericana de derechos humanos al establecer que "...el reconocimiento y el ejercicio del derecho a la verdad en una situación concreta constituye un medio de reparación..." (Caso Heliodoro Portugal Vs. Panama, 2008), así también dice "...que las víctimas de graves violaciones de derechos humanos y sus familiares, en su caso, tienen derecho a saber la verdad..." (Caso de los hermanos Gomez Paquiyauri Vs. Perú, 2004). Por lo tanto, el Estado a través de sus organismos de justicia debe procurar por todos los medios establecer la verdad de lo sucedido.

Así mismo, se determina que el reconocimiento del derecho de las personas víctimas a conocer la verdad de lo sucedido puede constituirse en un medio importante de reparación (Caso Tibi Vs. Ecuador, 2004), lo cual ya en el plano de la violencia intrafamiliar o domestica radica en la existencia, no solo de la víctima directa de la infracción, pues también tiene derecho a saber la verdad de lo sucedido, el momento en el que sucedió y el lugar en el cual se generaron los hechos de violencia contra la mujer en el ámbito familiar o domésticos sus familiares, constituyendo por lo tanto el derecho al conocimiento de la verdad como uno de los derechos de fundamental importancia dentro del campo de las victimas conforme así se ha determinado en el ámbito internacional de derechos humanos. Es decir, las víctimas tienen derecho a conocer de forma detallada la verdad histórica de los hechos de lo más real posible dentro de lo cual se incluye todos 
los patrones de actuación conjuntas en el hecho, así como de todas las personas y de las diversas formas de actuación que tuvieron cada uno de ellos (Caso González y Otras ("Campo Algodonero") Vs. Mexico , 2009).

En este punto debemos indicar que la Corte Interamericana dentro de los modelos de reparación ha determinado la existencia de víctimas individuales y colectivas, siendo aplicable para el caso en relación el primero de ellas, en donde para criterio de la Corte se produce cuando la violación de los derechos se ha producido en contra de una personas y su afectación resulta en contra de esta y de sus familiares independientemente de que estas hayan o no observado la violación y que estas tienen derecho a reclamar por diferentes circunstancias ya sea porque la víctima se encuentre desaparecida o muerta, pues se han convertido en víctimas directas de la vulneración principal (Becerra Becerra, 2014)

No solo el ámbito internacional de derechos humanos se ha pronunciado sobre el derecho de las víctimas a conocer la verdad sobre los hechos, también lo ha hecho el Estado ecuatoriano a través de la Corte Constitucional, misma que ha determinado que al haberse solicitado por parte de fiscalía la desestimación de una denuncia y el archivo del expediente por parte de la Unidad Especializada de Violencia de Genero de la Fiscalía de Esmeraldas, dentro de un caso en el cual NN resulta contagiado de VIH en un Hospital Público de Esmeraldas, ha vulnerado el derecho a la verdad y el derecho a la tutela judicial efectiva, así como el principio de interés superior del niño en concordancia con el derecho a la salud del mismo, dejando sin efecto dicha solicitud y disponiendo se realice una nueva investigación, disponiendo además a la Fiscalía cumpla con su rol (Sentencia N. 068-18SEP-CC, 2018).

\section{La restitución}

En los últimos años el país ha incorporado dentro del sistema penal normas para garantizar el derecho a la reparación integral, dentro del cual se contempla la restitución integral, al respecto el artículo 77 refiere "esta constituye un derecho y una garantía para interponer los recursos y las acciones dirigidas a recibir las restauraciones y compensaciones en proporción con el daño sufrido" (Codigo Orgánico Integral Penal, 2014), como vemos, esta disposición incorporada en el COIP, en vigencia desde el 2014, incorpora la restitutio in integrum de forma general.

El Código Orgánico Integral Penal desarrolla dentro de los mecanismos de reparación integral, la restitución, misma que refiere:

"se aplica a casos relacionados con el restablecimiento de la libertad, de la vida familiar, de la ciudadanía o de la nacionalidad, el retorno al país de residencia anterior, la recuperación del empleo o de la propiedad, así como al restablecimiento de los derechos políticos" (Codigo Orgánico Integral Penal, 2014). 
En el mismo sentido se encuentra determinado por la Asamblea General de las Naciones Unidas, en la Resolución Aprobada por la Asamblea General el 16 de diciembre del 2005, del sexagésimo período de sesiones, en el cual se encuentran contenidos los principios y directrices básicos sobre el derecho de las víctimas de violaciones manifiestas de las normas internacionales de derechos humanos y de violaciones graves del derecho internacional humanitario a interponer recursos y obtener reparaciones, resolución en la cual en su numeral 19, contempla:

"La restitución, siempre que sea posible, ha de devolver a la víctima a la situación anterior a la violación manifiesta de las normas internacionales de derechos humanos o la violación grave del derecho internacional humanitario. La restitución comprende, según corresponda, el restablecimiento de la libertad, el disfrute de los derechos humanos, la identidad, la vida familiar y la ciudadanía, el regreso a su lugar de residencia, la reintegración en su empleo y la devolución de sus bienes" (Naciones Unidas, 2006)

Si bien es cierto, se establece parámetros específicos en la normativa respecto a la restitución, no obstante, de ello, por convencionalidad es aplicable normativa internacional de Derechos Humanos en lo que corresponde a reparación integral. Sobre la restitución la Corte IDH ha manifestado que "la reparación del daño ocasionado por una responsabilidad internacional requiere, siempre que sea posible, la plena restitución (restitutio in integrum), la cual consiste en el restablecimiento de la situación anterior a la violación" (Caso Comunidad Indigena Sawhoyamaxa Vs. Paraguay, 2006).

No siempre será posible, ni en todos los casos en los que existe víctimas, se produzca la restitución a la situación anterior del derecho violado, por lo que, debe considerarse otro tipo de parámetros a fin se produzca la plena restitución dentro de las cuales se deberá tomar una serie de medidas tendientes no solo a garantizar el pleno respeto a los derechos que han resultado conculcados o vulnerados dentro del acto, sino también para que se produzca la reparación de todas las consecuencias sufridas por la infracción, estableciéndose de esta manera inter alia el pago de una indemnización como compensación por los daños ocasionados, misma, lo más justa posible y en base a todos los efectos y consecuencias sufridas como producto de la infracción (Caso de las Masacres de Ituango Vs. Colombia , 2006), en igual sentido se ha pronunciado la Corte IDH en otra de sus sentencias al determinar que en caso de imposibilidad de restituir la situación anterior a la violación de los derechos, esta se deberá considerar dentro de la indemnización compensatoria por el daño inmaterial causado a la víctima. (Caso Gonzales Lluy o Otros Vs. Ecuador, 2015)

Los casos de violencia intrafamiliar o domestica son casos críticos, en los cuales difícilmente se podría hablar de una restitución a la situación anterior a la violación del derecho, pues, por vivir en una sociedad con rezagos del patriarcado, sistema de dominación que mantenemos hasta la actualidad y que se resiste a desaparecer, resulta 
fundamental se tome medidas correctivas a efectos de una plena restitución de los derechos de la víctima. (Alberdi \& Matas, 2002)

Al respecto, la Corte IDH, sobre la restitución dentro de la reparación, manifiesta:

“...teniendo en cuenta la situación de discriminación estructural en la que se enmarcan los hechos ocurridos en el presente caso y que fue reconocida por el Estado, las reparaciones deben tener una vocación transformadora en dicha situación, de tal forma que las mismas tengan un efecto no solo restitutivo sino también correctivo. En este sentido, no es admisible una restitución a la misma situación estructural de violencia y discriminación..." (Caso González y Otras ("Campo Algodonero") Vs. Mexico, 2009).

En consecuencia, al no ser posible en muchos casos llegar a una simple restitución del estado anterior al derecho violado, corresponde al Estado entre otras cosas adoptar todos los mecanismos para que se produzca la reparación absoluta a satisfacción de la víctima.

\section{La indemnización}

La indemnización de daños materiales e inmateriales se constituye en otro de los parámetros a ser considerados dentro de la reparación integral a la víctima, dentro de la cual debe establecerse la compensación por todo el daño causado a la víctima como consecuencia de la infracción y pueda evaluarse en términos económicos (Codigo Orgánico Integral Penal, 2014)

El Consejo Económico y Social de las Naciones Unidas, en su informe de la Relatoría Especial sobre la violencia contra la mujer, sus causas y consecuencias, Yakin Ertürk, en su Artículo II - Indemnizaciones, establece:

“...La compensación por actos de violencia contra la mujer puede consistir en la concesión de una indemnización económica por las lesiones físicas y psicológicas sufridas, por la pérdida del empleo y de las oportunidades educativas, por la pérdida de prestaciones sociales, por daños a la reputación y a la dignidad así como por los gastos legales, médicos o sociales incurridos como consecuencia de la violencia..." (ONU: Comisión de Derechos Humanos, 20 Enero 2006)

La Corte IDH, ha desarrollado dentro de su jurisprudencia criterios para una efectiva indemnización, dentro de los cuales establece que dentro de la indemnización se debe considerar tanto el daño material como el inmaterial; a criterio de la Corte, dentro del daño material se encontraría "...la pérdida o detrimento de los ingresos de la víctimas, los gastos efectuados con motivo de los hechos y las consecuencias de carácter pecuniario que tengan un nexo causal con los hechos del caso" (Caso Fernandez Ortega y Otros Vs. México, 2010).

En lo que corresponde a la indemnización por el daño material se debe considerar el daño emergente, mismo que está constituido por daños inmediatos que dejo la infracción y por 
los gastos que las victimas deben generar para aplacar los daños inmediatos que esta dejo; $y$, el lucro cesante, que está conformado por los ingresos que las victimas dejaron de percibir como producto de la infracción. Tanto el daño emergente como el lucro cesante deben ser tomados en cuenta al momento de resolverse sobre el pago de la indemnización, mismos que serán cuantificados monetariamente acorde a la situación de la víctima y de los daños materiales causados. (Caso Chitay Nech y Otros Vs. Guatemala, 2010)

Mientras que, al hablar de la indemnización que correspondería realizarlo por el del daño inmaterial, este alcanzaría:

“...tanto los sufrimientos y las aflicciones causados a la víctima y a sus allegados, el menoscabo de valores muy significativos para las personas, así como las alteraciones, de carácter no pecuniario, en las condiciones de existencia de la víctima o su familia" (Caso Fernandez Ortega y Otros Vs. México, 2010)

La misma Corte IDH, también considera que dentro de los daños inmateriales correspondería a más de las consecuencias determinadas supra, incluirse lo concerniente al daño moral causado a las víctimas, mismas que también deberían ser cuantificadas al momento de determinarse la indemnización. (Caso Manuel Cepeda Vargas Vs. Colombia, 2010)

Otro de los rubros que deben ser considerados dentro de la indemnización corresponde a los costos y gastos en los que haya incurrido la víctima, dentro de los cuales deben ser considerados todas sus erogaciones o gastos ocasionados como producto de la búsqueda en obtener justicia, misma que deberá ser cuantificada en base al principio de equidad de acuerdo a los gastos que hayan sido señalados y justificados por las partes, siempre que su quantum sea razonable (Caso de la Masacre de las Dos Erres Vs. Guatemala, 2009)

Otro estado personal de pronunciamiento actual por la Corte IDH y que debe ser sujeto de indemnización corresponde a la reparación por el daño al proyecto de vida que provoca una infracción, para ello debemos entender como proyecto de vida al que:

"atiende a la realización integral de la persona afectada, considerando su vocación, aptitudes, circunstancias, potencialidades y aspiraciones, que le permiten fijarse razonablemente determinadas expectativas y acceder a ellas.

El "proyecto de vida" se asocia al concepto de realización personal que a su vez se sustenta en las opciones que el sujeto puede tener para conducir su vida y alcanzar el destino que se propone." (Caso Loayza Tamayo Vs. Perú, 1998)

Se establece que el daño al proyecto de vida es objeto de reparación integral, mediante un proceso indemnizatorio ya que, si bien es cierto al resolver sobre una indemnización se dispone el pago de un daño emergente y lucro cesante, sin embargo estos no abarcarían el daño al proyecto de vida, pues el lucro cesante únicamente permite cuantificar lo que 
la víctima deja de percibir a causa de la infracción, mientras que el proyecto de vida tiene un espectro mucho más amplio ya que está asociado a la realización integral de la persona afectada. (Caso Loayza Tamayo Vs. Perú, 1998)

El Estado ecuatoriano mediante reformas introducidas en el mes de febrero del 2018 al COIP, incorpora mecanismos de reparación integral en casos de violencia de genero contra las mujeres, determinado en el Art. 78.1 sobre la "Reparación de daño al proyecto de vida basado en el Derecho Internacional de los Derechos Humanos" (Ley Organica Integral para prevenir y erradicar la violencia contra las mujeres, 2018)

\begin{tabular}{|c|c|}
\hline \multicolumn{2}{|c|}{ PARÁMETROS DE INDEMNIZACIÓN } \\
\hline Daño Material & Daño Inmaterial \\
\hline Daño emergente & Medidas de restitución \\
\hline Lucro cesante & Rehabilitación \\
\hline \multirow{4}{*}{$\begin{array}{l}\text { Costos y gastos } \\
\text { generados }\end{array}$} & Indemnización \\
\hline & Medidas de satisfacción \\
\hline & Garantía de no repetición \\
\hline & Reparación por daño al proyecto de vida \\
\hline
\end{tabular}

\section{La rehabilitación}

Sobre la medida de Rehabilitación, la normativa determina que esta "se orientan a la recuperación de las personas mediante la atención médica y psicológica así como a garantizar la prestación de los servicios jurídicos y sociales necesarios para esos fines" (Codigo Orgánico Integral Penal, 2014)

La rehabilitación mantiene como finalidad la recuperación de las personas que han sido víctimas de una infracción, en este caso, de mujeres que han sido víctimas o de familiares de víctimas de violencia intrafamiliar o doméstica, recuperación a la que la víctima puede aproximarse o llegar siempre y cuando el Estado mediante sus funcionarios estatales adopten mecanismos de rehabilitación y disponga la respectiva atención médica, psicológica o psiquiátrica para su efectiva superación (Caso González y Otras ("Campo Algodonero") Vs. Mexico , 2009)

Ecuador en el 2018 dentro de sus reformas al sistema penal, incorpora medidas de rehabilitación dentro de los mecanismos de reparación integral en casos de violencia de genero contra las mujeres, estableciendo que, se "dispondrá la rehabilitación física, psicológica, ocupacional o educativa de la víctima directa y de las víctimas indirectas" (Ley Organica Integral para prevenir y erradicar la violencia contra las mujeres, 2018), rehabilitación que corresponde al Estado por medio de sus instituciones públicas, pues, este debe ofrecer y otorgar a las víctimas de violencia domestica por mandato legal, el tratamiento médico y psicológico previa aceptación y acuerdo informado con la víctima, tratamiento que debe ser inmediato, prolongado hasta su completo restablecimiento 
médico o psicológico y totalmente gratuito dentro de los cuales se incluye la entrega de medicamentos procurándose que la misma se produzca en el lugar más cercano al domicilio de la víctima y sea individualizado cumpliendo con sus necesidades y expectativas. (Calderon, 2013)

\section{La satisfacción del derecho violado}

Dentro de los mecanismos de reparación integral determinados en la legislación ecuatoriana, se establece las que corresponden a:

"medidas de satisfacción o simbólicas: se refieren a la declaración de la decisión judicial de reparar la dignidad, la reputación, la disculpa y el reconocimiento público de los hechos y las responsabilidades, las conmemoraciones y los homenajes a las víctimas, la enseñanza y la difusión histórica de la verdad” (Codigo Orgánico Integral Penal, 2014)

Claro está, que los casos de violencia intrafamiliar o doméstica en Ecuador tienen el carácter de reservados evitándose su publicidad por mandato legal por lo que, se deben aplicar todas las medidas de satisfacción posibles dentro de las cuales las disculpas públicas por los hechos, las declaraciones que deben contener las decisiones judiciales para reparar la dignidad y la reputación, publicación de ciertos párrafos de las sentencias, entre otros mecanismos de satisfacción, todo lo cual con el consentimiento de la víctima (Caso Fernandez Ortega y Otros Vs. México, 2010); en el mismo sentido se ha pronunciado la Corte IDH, al manifestar que “...el Estado tiene el deber de adoptar medidas positivas, concretas y orientadas a la satisfacción del derecho a una vida digna, en especial cuando se trata de personas en situación de vulnerabilidad y riesgo, cuya atención se vuelve prioritaria" (Caso Comunidad Indigena Yakye Axa Vs. Paraguay, 2005)

Conforme determina la normativa ecuatoriana, al momento de decidirse sobre la reparación integral de la víctima, debe aplicarse estándares internacionales de derechos humanos, lo cual conlleva a que, en la administración de justicia al momento de resolverse un caso por violencia intrafamiliar o domestica del cual se haya determinado la responsabilidad al infractor se debe disponer la reparación integral a la víctima considerándose para ello los estándares internacionales y al respecto se ha establecido en la jurisprudencia de la Corte IDH, que uno de los parámetros corresponde a disponerse medidas de satisfacción del derecho violado, dentro de los cuales la publicación o difusión de la sentencia, un acto público de reconocimiento de la responsabilidad, medidas en conmemoración de las víctimas o hechos y derecho, concederse becas de estudio o becas conmemorativas, medidas socioeconómicas de reparación colectiva, entre otras que puede aplicarse tomando en consideración las circunstancias de los hechos lesivos ya que estas medidas de satisfacción tienen como finalidad el de reintegrar la dignidad de la víctima y ayudar a reorientar su vida o su memoria. (Calderon, 2013)

\section{Las garantías de no repetición}


El último de los mecanismos de reparación integral determinados en la normativa penal corresponde a la Garantía de no Repetición, misma que establece:

"Se orientan a la prevención de infracciones penales y a la creación de condiciones suficientes para evitar la repetición de las mismas. Se identifican con la adopción de las medidas necesarias para evitar que las víctimas sean afectadas con la comisión de nuevos delitos del mismo género" (Codigo Orgánico Integral Penal, 2014)

Sobre las garantías de no repetición de los hechos, la Corte IDH se ha pronunciado en el sentido que esta corresponde a una tarea del Estado, pues la vía para garantizar la no repetición de los hechos corresponde a políticas públicas que debe generar e implementar el Estado, dentro de las cuales, mecanismos de investigación, sanción y sobre todo prevención y erradicación de la violencia de género (Caso Fernandez Ortega y Otros Vs. México, 2010); las garantías de no repetición lo que buscan es, evitar que en lo posterior se produzcan nuevos actos de violencia lo cual se puede lograr siempre que el Estado realice sus mejores esfuerzos encaminados para ello a través de los mecanismos legales, institucionales y otros. (Ron, 2015)

\section{Metodología}

La investigación se ha realizado desde una metodología bibliográfica (cualitativa) mediante la cual se analizó documentos relevantes al tema; la legislación nacional, convenios internacionales, sentencias de la Corte IDH y Corte Constitucional.

\section{Resultados}

Con la información académica obtenida nos ha permitido establecer claramente los tipos de violencia que se generan en el ámbito intrafamiliar. Además se ha llegado a establecer los parámetros y mecanismos que se deben abordar para que la reparación integral sea aplicada de manera efectiva y eficaz.

\section{Conclusiones}

- En el 2008 al entrar en vigencia la Constitución de la República del Ecuador se fija como un derecho elevado a garantía constitucional la reparación integral a las víctimas, a partir de lo cual se desarrolla normativa infra constitucional a efectos de establecer parámetros y estándares para una efectiva reparación, es así que a partir del año 2014 y posteriores reformas del 2018 y 2019 el sistema penal ecuatoriano configura normativa específica sobre violencia contra la mujer; primero a efectos de sancionar los actos que afecten sus derechos, verificándose que, en lugar de disminuir este tipo de infracciones entre el 2011 con un $60.6 \%$ de algún tipo de violencia contra la mujer, al 2019 se incrementaron a un 64.9\%, dentro de las cuales, los ámbitos donde se produce la mayor cantidad de actos de violencia de genero contra la mujer lo constituye el ámbito familiar o doméstico, siendo provocado por la actual pareja o ex conviviente predominando la violencia de tipo psicológico con un seguido por la violencia física, sigue la violencia 
patrimonial o económica para ubicarse en la última escala de violencia de tipo sexual conforme se ha establecido en la presente investigación; y, segundo, se incorpora normativa encaminada a procurar la reparación integral de la víctima.

- A partir del 2018 que entra en vigencia la Ley Organica Integral para prevenir y erradicar la violencia contra las mujeres, desarrolla de mejor manera los parámetros y estándares que deben aplicarse al momento de disponer una reparación integral debiendo disponerse la reparación material e inmaterial conforme los parámetros determinados en la presente investigación en los cuales se incluye daño emergente, lucro cesante, costas y gastos, medidas encaminadas a la restitución del derecho vulnerado, a rehabilitar e indemnizar por el perjuicio causado, medidas de satisfacción del derecho vulnerado, garantías de no repetición inclusive sobre el daño al proyecto de vida de la víctima.

- En la actualidad, dentro de los parámetros de las reparaciones a las víctimas de infracciones debe incluirse la reparación por la afectación a su proyecto de vida, así lo establece la Jurisprudencia de la Corte IDH, pues no basta con generar una indemnización por los daños provocados al momento de la infracción y de lo que la víctima dejo de percibir en lo posterior por efectos de la infracción, pues, debe producirse la indemnización de acuerdo a los daños provocados al no poder cumplir con su realización personal en toda su dimensión.

\section{Referencia Bibliográfica}

Alberdi, I., \& Matas, N. (2002). La Violencia Domestica. Barcelona: La Caixa.

Becerra Becerra, Z. (18 de 12 de 2014). Algunas consideraciones en torno al modelo de reparaciones en el sistema interamericano de derechos humanos. Dereito: Revista xurídica Da Universidade De Santiago De Compostela, 23(2), 57-77. Recuperado el 11 de Julio de 2021, de Recuperado a partir de https://revistas.usc.gal/index.php/dereito/article/view/2224

Calderon, J. (2013). la Reparación Integral en la Jurisprudencia de la Corte Interamericana de Derechos Humanos: estándares aplicables al nuevo paradigma mexicano. Instituto de Investigaciones Juridicas de la UNAM. Obtenido de https://www.corteidh.or.cr/tablas/r33008.pdf

Caso Acevedo Jaramillo y otros Vs. Perú (Corte Interamericana de Derechos Humanos 07 de Febrero de 2006).

Caso Chitay Nech y Otros Vs. Guatemala (Corte Interamericana de Derecos Humanos 25 de Mayo de 2010).

Caso Comunidad Indigena Sawhoyamaxa Vs. Paraguay (Corte Interamericana de Derechos Humanos 29 de Marzo de 2006). 
Caso Comunidad Indigena Yakye Axa Vs. Paraguay (Corte Interamericana de Derechos Humanos 17 de Junio de 2005).

Caso de la Masacre de las Dos Erres Vs. Guatemala (Corte Interamericana de Derechos Humanos 24 de Noviembre de 2009).

Caso de las Masacres de Ituango Vs. Colombia (Corte Interamericana de Derechos Humanos 01 de Julio de 2006).

Caso de los hermanos Gomez Paquiyauri Vs. Perú (Corte Interamericana de Derechos Humanos 08 de 07 de 2004).

Caso Fernandez Ortega y Otros Vs. México (Corte Interamericana de Derechos Humanos 30 de Agosto de 2010).

Caso Gonzales Lluy o Otros Vs. Ecuador (Corte Interamericana de Derechos Humanos 01 de Septiembre de 2015).

Caso González y Otras ("Campo Algodonero") Vs. Mexico (Corte Interamericana de Derechos Humanos 16 de Noviembre de 2009).

Caso Heliodoro Portugal Vs. Panama (Corte Interamericana de Derechos Humanos 12 de Agosto de 2008).

Caso Loayza Tamayo Vs. Perú (Corte Interamericana de Derechos Humanos 27 de Noviembre de 1998).

Caso Manuel Cepeda Vargas Vs. Colombia (Corte Interamericana de Derechos Humanos 25 de Mayo de 2010).

Caso Tibi Vs. Ecuador (Corte Interamericana de Derechos Humanos 07 de Septiembre de 2004).

Codigo Orgánico Integral Penal. (10 de Febrero de 2014). Mecanismos de Reparación Integral. Quito: Registro Oficial.

Constitución de la República del Ecuador. (20 de Octubre de 2008). Derechos de Protección. Quito, Pichincha, Ecuador: Registro Oficial.

Instituto Nacional de Estadisticas y Censos. (2011). Encuesta Nacional de Relaciones Familiares y Violencia de Genero contra las Mujeres. Quito. Recuperado el 20 de Julio de 2021, de https://www.ecuadorencifras.gob.ec//documentos/webinec/Estadisticas_Sociales/sitio_violencia/presentacion.pdf

Instituto Nacional de Estadisticas y Censos. (2019). Encuesta Nacional sobre Relaciones Familiares y Violencia de Género contra las Mujeres - ENVIGMU 2019. Quito: INEC.

Justicia, P. d. (2020). Ecuador Patente no 0072-AJ-CNJ-2020. 
Karina, T., Ana, B., \& Wnellis, B. (2010). Tratamiento juridico de la violencia doméstica en Colombia, Ecuador y Venezuela (Vols. 6 N.- 13). (U. A. Caribe, Ed.) Barranquilla: Justicia Juris ISSN-e 1692-8571. Recuperado el 04 de 07 de 2021, de https://dialnet.unirioja.es/servlet/articulo?codigo=3634141

Ley contra la violencia a la mujer y la familia. (11 de Diciembre de 1995). Formas de violencia intrafamiliar. Quito: Registro Oficial.

Ley Organica Integral para prevenir y erradicar la violencia contra las mujeres. (05 de Febrero de 2018). Tipos de Violencia Intrafamiliar. Quito: Registro Oficial.

Ley Reformatoria al Código Orgánico Integral Penal. (24 de Diciembre de 2019). Quito : Registro Oficial.

Naciones Unidas. (2006). Principios y directrices básicos sobre el derecho de las víctimas de violaciones manifiestas de las normas internacionales de derechos humanos y de violaciones graves del derecho internacional humanitario a interponer recursos y obtener reparaciones. Resolución de las Naciones Unidas, Nueva York. Recuperado el 17 de Julio de 2021, de http://www.pge.gob.ec/images/blog/casoisaias2015/isaiasAnexos/RESOLUCIO N_60_147_ASAMBLEA_GENERAL_ONU.pdf

ONU. (1996). Informe de la Cuarta Conferencia Mundial sobre la Mujer - Beijing. New York:

https://www.un.org/womenwatch/daw/beijing/pdf/Beijing\%20full\%20report\%2 0S.pdf.

ONU. (2006). Estudio a fondo sobre todas las formas de violencia contra la mujer. Nueva York: https://www.acnur.org/fileadmin/Documentos/BDL/2016/10742.pdf.

ONU: Comisión de Derechos Humanos. (20 Enero 2006). Integración de los derechos humanos de la mujer y la perspectiva de género: Violencia contra la mujer: La norma de la debida diligencia como instrumento para la eliminación de la violencia contra la mujer. Nueva York: E/CN.4/2006/61. Recuperado el 18 de 07 de 2021 , de https://www.refworld.org.es/category,REFERENCE,UNCHR,,,4d5a65db2,0.ht $\mathrm{ml}$

Presidencia de la Corte Nacional de Justicia de Ecuador. (14 de 01 de 2020). Infracciones contra la mujer o miebros del nucleo familiar - parametros legales para determinar la reparación integral. Quito: https://www.cortenacional.gob.ec/cnj/images/pdf/consultas_absueltas/Penales/in fraccionviolencia/031.pdf.

Ron, X. (2015). Los estandares interamericanos en la reparación integral en la jurisprudencia de la Corte Constitucional del Ecuador. Quito. Obtenido de 
https://repositorio.uasb.edu.ec/bitstream/10644/4700/1/PI-2015-17-RonLos\%20estandares.pdf

Sentencia N. 068-18-SEP-CC, Caso N.- 1529-16-EP (Corte Constitucional del Ecuador 21 de Febrero de 2018).

Storini, C. (2014). El concepto de reparación integral y su aplicación en Colombia y Ecuador. Quito: Universidad Andina Simón Bolívar, sede Ecuador.

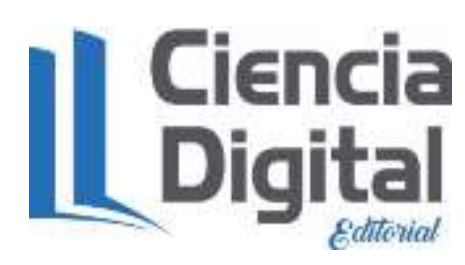




\section{PARA CITAR EL ARTÍCULO INDEXADO.}

Espín Rojas, F. L., \& Sánchez Oviedo, D. X. (2021). Víctimas de violencia intrafamiliar y la reparación integral en el Ecuador. ConcienciaDigital, 4(4), 28-50. https://doi.org/10.33262/concienciadigital.v4i4.1883

\section{Liencia}

El artículo que se publica es de exclusiva responsabilidad de los autores y no necesariamente reflejan el pensamiento de la Revista Conciencia Digital.

El artículo queda en propiedad de la revista y, por tanto, su publicación parcial y/o total en otro medio tiene que ser autorizado por el director de la Revista Conciencia Digital.

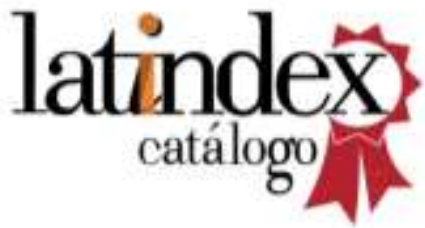

